\title{
Clandestine Abortions in Cameroon: Risk Factors for Severe Complications
}

\author{
ELIE NKWABONG ${ }^{1}$, EFUETNKENG BECHEM ${ }^{2}$, JOSEPH NELSON FOMULU ${ }^{3}$
}

\begin{abstract}
:
Objective (s): The aim of this study was to identify risk factors for severe complications (SC) of clandestine abortions.

Methods: This retrospective descriptive study was conducted between March $1^{\text {st }}$ and August $31^{\text {st }}, 2012$ in the maternities of the University Teaching Hospital and the Central Hospital, Yaoundé (Cameroon). Files of women with clandestine abortions were recruited. Main variables studied were maternal age, parity, gestational age, the method used, the time interval between abortion and consultation, the complications presented. Data of women with SC were compared to those of women who had with non severe or no complications (NC). Fisher exact test and student $t$ test were used for comparison. The significance level was $p=0.05$.
\end{abstract}

Results: Amongst 94 women, 76 (80.9\%) had SC against 18 (19.1\%) with NC.Risk factors for SC were gestational age e"12 weeks (OR 2.7, 95\% Cl 0.8-8.9), abortion carried out with dilatation and curettage/evacuation (OR 2.4, 95\% Cl 0.6-9.2) or with intramuscular injection of a non specified medication (four cases against zero respectively), by a nurse (OR 1.4, 95\% Cl 0.54.1), by a friend (nine cases against zero respectively) or a traditional healer (three cases against zero respectively). Other risk factors were abortion carried out in a primary health center (OR 1.5, 95\% Cl 0.4-4.7) and late consultation after abortion $(P=0.0404)$.

Conclusions: For prevention of severe post abortal complications, women and abortionists should be informed on these risk factors.

Key words: Clandestine abortions -Severe complications -Risk factors.

\section{Introduction:}

Induced abortion rate is still increasing due mainly to the rise of number of women of reproductive age. ${ }^{1}$ Due to the fact that abortion is illegal in Cameroon, most of these unwanted pregnancies end up in clandestine abortions. Many methods of inducing abortion are used. They include medical methods using prostaglandins $\mathrm{E}$ and $F_{2 a ́}$, surgical methods with curettage or manual vacuum aspiration and traditional methods taken orally, inserted vaginally or rectally. ${ }^{2,3}$ Complications of unsafe abortions occur more among induced than among spontaneous abortions. ${ }^{4}$ Immediate and short term complications include hemorrhage from incomplete abortion or genital tract lacerations, uterine perforation with or without bladder or intestine injuries, pelvic infections, pelviperitonitis or generalized peritonitis, vesico-vaginal or vesico-uterine fistulas and also maternal death. ${ }^{4,5}$ Long term complications are Asherman syndrome, infertility, abnormal placental insertion and even psychiatric complications. ${ }^{6}$ These complications are frequent if the procedure is done by an unqualified health provider or in unsafe conditions. ${ }^{4}$ No study in our country has evaluated risk factors for severe complications in clandestine abortions. The aim of this study, therefore, was to evaluate such risk factors in order to efficiently fight against these complications.

1. Senior Lecturer; Department of Obstetrics \& Gynecology; University Teaching Hospital/ Faculty of Medicine and Biomedical Sciences, Yaoundé (Cameroon).

2. Resident; Department of Obstetrics \& Gynecology; Faculty of Medicine and Biomedical Sciences, Yaoundé (Cameroon).

3. Professor; Department of Obstetrics \& Gynecology; University Teaching Hospital/ Faculty of Medicine and Biomedical Sciences, Yaoundé (Cameroon). 


\section{Material and methods:}

This retrospective descriptive study was conducted between March $1^{\text {st }}$ and August $31^{\text {st }}, 2012$ (six months) in the maternity of the University Teaching Hospital and the Central Maternity of Yaoundé, Cameroon. All women with clandestine abortion were recruited. Variables studied were maternal age, parity, gestational age at abortion, the abortionist, the method used, the duration of antibiotic cover, the time interval between abortion and consultation in our service, the complications presented and the duration of admission in our units.

Complication was said to be severe if it was either fatal, if there were post abortal sepsis (incomplete septic abortion, pelvic infection, septic shock), severe anemia (hemoglobin level $<7 \mathrm{~g} / \mathrm{dl}$ ), hypovolemic shock (systolic blood pressure $<80 \mathrm{mmHg}$ ), uterine perforation with or without peritonitis. Complication was non severe if it was an incomplete abortion and needed only uterine evacuation under antibiotic cover, with good general status. Four patients with no complication (complete abortion) were included in the non severe complication group for analysis.

An informed consent form was obtained from each patient (or her family) and this study was approved by the two institutional ethics committees. Data were subsequently analyzed using SPSS 18.0.

Data of women with severe complications were compared with those of women with non severe complications. Pearson chi square test or Fisher exact test and unpaired student $t$ test were used where appropriate for comparison. The significance level was $p=0.05$.

\section{Results:}

Ninety four clandestine abortions were recorded. Amongst them 76 (80.9\%) had severe complications (SC) against 18 (19.1\%) with non severe complications or no complication at all (NC). The SC cases included 28 cases of severe anemia that needed blood transfusion, 19 cases of pelvic infection, 16 cases with hypovolemic shock, 6 cases of uterine perforation, 3 cases of septic shock, 2 cases of generalized peritonitis and 2 cases of maternal death. The NC cases included 14 cases of incomplete abortion (with or without moderate or mild anemia) and 4 cases with no complication.

Maternal ages ranged between 17 and 41 years, with a mean of $25.3 \pm 4.8$ years in the SC group and between 16 and 32 years, with a mean of $22.2 \pm 4.5$ years in the NC group $(P=0.014)$.

Parities ranged between 0 and 6 with a median parity 4 in the SC group and between 0 and 3, with a median parity 2 in the NC group ( $P=0.006)$.

The gestational ages ranged between 5 and 20 weeks, with a mean of $11.2 \pm 3.1$ weeks in the SC group and between 5 and 22 weeks, with a mean of $10.1 \pm 4.4$ weeks in the NC group $(P=0.217)$. Nevertheless, of the 37 women whose gestational age was 12 weeks or above $33(89 \%)$ had severe complications as against $41 / 57$ (71.9\%) for those of 11 weeks or less even though the difference was not statistically significant (OR 2.7, 95\% Cl 0.8-8.9) (Table 1).

Table-I

Gestational age at abortion in relation to severity of complications.

\begin{tabular}{lcc}
\hline Gestational age (weeks) & Mild or no complications $\mathrm{n}(\%)$ & Severe complicationsn (\%) \\
\hline $5-7$ & $5(27.8)$ & $6(8)$ \\
$8-9$ & $4(22.2)$ & $20(26.3)$ \\
$10-11$ & $5(27.8)$ & $17(22.4)$ \\
$12-13$ & $2(11.1)$ & $17(22.4)$ \\
$\geq 14$ & $2(11.1)$ & $16(21.0)$ \\
\hline Total & $18(100)$ & $76(100)$ \\
\hline
\end{tabular}


Main abortionists were nurses in 49 cases $(64.5 \%)$ in the SC group against 10 (55.6\%) in the NC group (OR $1.4,95 \% \mathrm{Cl} 0.5-4.1, \mathrm{P}=0.58$ ) and general practitioners involved in 11 cases (14.5\%) in the SC group against $3(16.7 \%)$ in the NC group (OR 0.8, 95\% $\mathrm{Cl} 0.2-3.4$, $\mathrm{P}=1$ ) (Table 2).

The procedure took place mainly in a primary health center in 28 cases with SC (36.9\%) against $5(27.8 \%)$ in the NC group (OR 1.5, 95\% Cl 0.4-4.7, $\mathrm{P}=0.58$ ) and in the provider's or patient's home in 31 cases $(40.8 \%)$ in the SC group against 8 (44.4\%) in the NC group (OR 0.8, 95\% Cl 0.3-2.4, P=0.79) (Table 3).

Commonest methods used for terminating pregnancy was dilatation \& curettage (D\&C) or dilatation \& evacuation (D\&E) used in 25 cases with SC (32.9\%) against $3(16.7 \%)$ in the NC group (OR $2.4,95 \% \mathrm{Cl}$ $0.6-9.2, \mathrm{P}=0.25)$ and MVA used in 29 cases (38.2\%) in the SC group against eight (44.4\%) in the NC group (OR 0.7, 95\% Cl 0.2-2.2, $\mathrm{P}=0.78$ ) (Table 4).

In the SC group, mean duration of antibiotic use was $3.7 \pm 3.6$ (range $0-14$ ) against $2.6 \pm 3.1$ (range $0-10$ ) days in the NC group $(P=0.23)$.
In our study, the time lapse between abortion and consultation in our service varied between 0 and 90 days with a mean of $15.1 \pm 16.0$ days in the SC group while in the $\mathrm{NC}$ group it varied between 0 and 30 days with a mean of $7.0 \pm 8.1$ days $(P=0.04)$.

There were 2 cases of maternal death in the SC group due in one case to generalized body swelling that followed an intramuscular injection of an unknown medication at 8 weeks gestation (autopsy not done) and in the other case to septic shock. In fact that patient had curettage at 14 weeks and consulted only three months after abortion. She had a tubo-ovarian abscess that ruptured giving rise to generalized peritonitis and later to septic shock and death despite emergency laparotomy.

Hospital stay varied between 1 and 21 days with a mean of $3.97 \pm 0.89$ days in the SC group while in the $\mathrm{NC}$ group it varied between 1 and 4 days with a mean of $1.34 \pm 0.9$ days $(P<0.0001)$.

The longest hospital stay was observed in the patient who died of a septic shock. Patient developed

Table-II

Abortionist distribution in relation to severity of complications.

\begin{tabular}{lccccc}
\hline Abortionist & $\begin{array}{c}\text { Severe } \\
\text { complications }\end{array}$ & $\begin{array}{c}\text { Non severe } \\
\text { complications }\end{array}$ & OR & $95 \% \mathrm{Cl}$ & $\mathrm{P}$ \\
\hline Nurses & 49 & 10 & 1.4 & $0.5-4.1$ & 0.589 \\
General practitioner & 11 & 3 & 0.84 & $0.2-3.4$ & 1 \\
A friend & 9 & 0 & - & - & 0.198 \\
Self-induction & 4 & 4 & 0.2 & $0.04-0.8$ & 0.041 \\
Traditional healers & 3 & 0 & - & - & 1 \\
Consultant in Obst \& Gyn & 0 & 1 & - & - & - \\
\hline Total & 76 & 18 & & & \\
\hline
\end{tabular}

OR: odd ratio.

Table-III

Places of abortion distribution according to severity of complications.

\begin{tabular}{lccccc}
\hline $\begin{array}{l}\text { Places where abortion } \\
\text { took place }\end{array}$ & $\begin{array}{c}\text { Severe } \\
\text { complications }\end{array}$ & $\begin{array}{c}\text { Non severe } \\
\text { complications }\end{array}$ & OR & $95 \% \mathrm{Cl}$ & $\mathrm{P}$ \\
\hline Primary health centers & 28 & 5 & 1.5 & $0.4-4.7$ & 0.587 \\
Abortionist's or patient's home & 31 & 8 & 0.86 & $0.3-2.4$ & 0.785 \\
Private clinics & 16 & 4 & 0.98 & $0.7-1.2$ & 1 \\
Hospital & 1 & 1 & 0.2 & $0.01-3.8$ & 0.347 \\
\hline Total & 76 & 18 & & & \\
\hline
\end{tabular}

OR: odd ratio. 
Table-IV

Severity of complications distribution in relation to methods used.

\begin{tabular}{lccccc}
\hline Method used & $\begin{array}{c}\text { Severe } \\
\text { complications }\end{array}$ & $\begin{array}{c}\text { Non severe } \\
\text { complications }\end{array}$ & OR & $95 \% \mathrm{Cl}$ & $\mathrm{P}$ \\
\hline D\&C or D\&E & 25 & 3 & 2.4 & $0.6-9.2$ & 0.253 \\
Transcervical foreign body & 4 & 1 & 0.9 & $0.09-9.0$ & 1 \\
MVA & 29 & 8 & 0.7 & $0.2-2.2$ & 0.79 \\
Misoprostol & 9 & 4 & 0.4 & $0.1-1.7$ & 0.26 \\
IM injection** & 4 & 0 & - & - & 0.58 \\
Traditional methods & 3 & 1 & 0.7 & $0.06-7.1$ & 1 \\
Amniotomy & 1 & 1 & 0.2 & $0.01-3.8$ & 0.348 \\
Potassium permanganate & 1 & 0 & - & - & - \\
\hline Total & 76 & 18 & & & \\
\hline
\end{tabular}

11. D\&C: dilatation \& curettage, D\&E: dilatation \& evacuation, MVA: manual vacuum aspiration, IM: intramuscular, OR: odd ratio.

12. * Various objects used.

13. ** Drug used not specified.

14. ${ }^{* * *}$ Inserted in the vagina.

generalized peritonitis due to ruptured tuboovarian abscess, which developed as a consequence of curettage done 3 months ago. Abscess drainage and peritoneal toileting was done on laparotomy but unfortunately she developed further complications and warranting a repeat laparotomy. She developed septic shock and died after few hours of operation.

\section{Discussion:}

A total of 76 women (80.9\%) with clandestine abortion had severe complications in our series. This can be explained by the fact that most abortionists (79 or $84 \%$ ) were not qualified enough to terminate pregnancies. Only $15(16 \%)$ were theoretically qualified to terminate pregnancy in our study (general practitioners and gynecologists). Our rate of $80.9 \%$ of women with severe complications is higher than the rate of $16 \%$ women with severe complications from unsafe abortion in Thailand. ${ }^{5}$ This great difference might be due to the fact that in Srinil's series, intrauterine chemical injection was the most frequently used method in severe complication group while in our study many methods including dilatation and curettage/ evacuation, MVA, misoprostol, transcervical foreign body, intramuscular injection of non specified drugs and traditional methods were used. Moreover, since abortion is illegal in Cameroon, only complicated cases come to hospitals.
In our study, mean gestational age in SC group was a bit higher than that of NC group although the difference was not statistically significant. In our study, women whose gestational age was 12 weeks and above had more severe complications than those whose gestational age was 11 weeks or less (OR $2.7,95 \% \mathrm{Cl}$ $0.8-8.9)$. This is similar to other studies which found that increasing gestational age was associated with an increased risk of severe complication following induced abortion. 7,8

In our series, abortionists were mainly untrained health providers (nurses) in the SC group (49/76 or $64.5 \%$ ) as already observed by others. ${ }^{4,9}$

Abortions were performed mainly at abortionist's or patient's home (41.6\%), in a health center (35.1\%), in a private clinic $(21.2 \%)$ and rarely in a hospital (2.1\%). Tadesse et al noticed that $60 \%$ of the abortions were carried out at the abortionist's home and $35 \%$ at the patient's home. He observed that only $5 \%$ were done in the hospital by professionals. ${ }^{9}$ In our study, abortions carried out in primary health centers were associated with an increased risk of severe complications (OR 1.5, 95\% Cl 0.4-4.7). This can be explained by the fact that those abortions were carried out by nurses.

The method mostly associated with severe complications was D\&C or D\&E (OR $2.4,95 \% \mathrm{Cl}$ 0.69.2). This is close to the findings of Pereira et al in 
Portugal who noticed that among surgical methods, curettage caused more blood loss than MVA. ${ }^{10}$ Furthermore, some authors noticed that curettage was associated with increased risk of uterine perforation than MVA. ${ }^{4}$

A total of five women (5.3\%) inserted foreign body through their cervix. In the series of Tadesse et al, $32.1 \%$ of their patients inserted plastic tube per vagina. $^{9}$

Mean time between abortion and consultation in our series (13.7 days) was longer in the SC group even though the difference was not statistically significant. This could explain severe anemia and also infection in our patients since antibiotic cover was usually short (mean:3.7 days).

Mean duration of admission was significantly prolonged in the SC group especially among those women with infectious processes. In the NC group a few women remained in the hospital for up to four days because they were waiting for money to pay for their hospital bills.

The longest admission was observed in a woman whose abortion was carried out with curettage showing once more that this method should be used less often.

Maternal death rate in our series (2.1\%) was a bit higher than the $1.17 \%$ observed among 170 cases of unsafe abortion in Srinil's series. ${ }^{5}$

\section{Conclusion:}

As shown in this study, risk factors for severe complications following clandestine abortion were higher gestational age, abortion carried out with dilatation and curettage/evacuation or with intramuscular injection of a non specified medication, by a nurse, by a friend or a traditional healer. Other risk factors were abortion carried out in a primary health center and prolonged delay between abortion and consultation. Therefore, women and abortionists should be informed on these risk factors. Women should aware about the complications of unsafe abortion by unskilled personnel and they should go to appropriate place, which is ideal and safe for termination of pregnancy.

\section{References:}

1. Shah I and Ahman E.Unsafe abortion in 2008: global and regional levels and trends. Reprod Health Matters 2010; 18(36): 90-101.

2. Rasch V. Unsafe abortion and post abortion care - an overview. Acta Obstet Gynecol Scand 2011; 90(7): 692-00.

3. Grossman D, Holt K, Peña M, Lara D, Veatch M, Córdova D, Gold M, Winikoff B and Blanchard K. Self-induction of abortion among women in the United States. Reprod Health Matters 2010; 18(36): 136-46.

4. Shah N, Hossain N, Noonari M and Khan NH. Maternal mortality and morbidity of unsafe abortion in a university teaching hospital of Karachi, Pakistan. J Pak Med Assoc 2011; 61(6): 582-6.

5. Srinil S. Factors associated with severe complications in unsafe abortion. J Med Assoc Thai 2011; 94(4): 408-14.

6. Gurpegui $M$ and Jurado D. [Psychiatric complications of abortion][Article in Spanish]. Cuad Bioet 2009; 20(70): 381-92.

7. Manual MJ, Niinimäki M, Suhonen S, Hemminki E, Gissler M and Heikinheimo O. Immediate adverse events after second trimester medical termination of pregnancy: results of a nationwide registry study. Hum Reprod 2011; 26(4): 92732.

8. Andersen K, Ganatra B, Stucke S, Basnett I, Karki YB and Thapa K. A prospective study of complications from comprehensive abortion care services in Nepal. BMC Public Health 2012; 12:9. doi: 10.1186/1471-2458-12-9.

9. Tadesse E, Yoseph S, Gossa A, Muletta E, Pogharian D, Ketsella K and Hawaz Z. Illegal abortions in Addis Ababa, Ethiopia. East Afr Med J 2001; 78(1): 25-9.

10. Pereira PP, Oliveira AL, Cabar FR, Armelin AR, Maganha CA and Zugaib M. [Comparative study of manualvacuum aspiration and uterine curettage for treatment of abortion][Article in Portuguese]. Rev Assoc Med Bras 2006; 52(5): 304-7. 